\title{
Interactive comment on "Repeated
} electromagnetic induction measurements for mapping soil moisture at the field scale: validation with data from a wireless soil moisture monitoring network" by E. Martini et al.

\section{Anonymous Referee \#2}

\section{Received and published: 17 April 2016}

For the most part this is a well-written manuscript that clearly describes what was done in the study. The methods and analysis are sound, and the results make a meaningful contribution to our understanding of EMI techniques and their relationship (or lack thereof, in some cases) to soil water content. I have just a few minor comments and suggestions for the authors.

Page 2, Line 20 - "To a higher clay..." should be "A higher clay..."

Page 2, Line 25 - In addition to Corwin et al., 2008, I suggest citing Brevik and Fenton, 2004, which may be the first published field study working with EMI that addressed 
this.

Page 2, Lines 24-26 - In addition to Doolittle et al., 2001 in line 24 I suggest citing Heilig et al., 2011. In addition to Abdu et al., 2008 in line 25 I suggest citing Heil and Schmidhalter, 2012. And in addition to Al-Gaadi, 2012 in line 26 I suggest citing Brevik and Fenton, 2004 and Islam et al., 2014. This enhances the citations a bit and makes the three citations suddenly used for soil organic carbon in line 27 not look so out of place (only 1 citation is used for every idea in this section except for SOC). Another citation or two for some of the other ideas where I haven't made specific suggestions wouldn't be a bad thing either.

Page 5, Line 23 - What is the status of the Wollschläger et al., submitted paper? Has it been accepted yet? If not, it should be removed. There is no guarantee that a submitted paper will be accepted. If it is not accepted, this paper ends up with a reference to something that does not exist.

Page 8, Lines 7-8 - This sentence could use a reference to a situation where equipment in the field has been documented to cause issues for EMI surveys, such as Lamb et al., 2005.

Page 13, Line 26 - “. . measured with EMI." This should be changed to ". . measured with EMI at this location." Given the proven site-specific nature of EMI applied to soils studies and the relatively strong correlations that have been recorded between soil water content and EMI at some other locations, it seems important to acknowledge that this statement is not necessarily valid at all locations.

Figure 4 - The individual graphs are so small they are difficult to read. If there is a way to increase their size (maybe portrait orientation rather than landscape?) it would be beneficial. Also, the caption says ". . as well as p-values, when significant. ..". However, every $p$ value on every graph that has one says " $p<0.05$ ". If that is what is going to be entered, you may as well just have a symbol, such as *, that goes behind every $\mathrm{R} 2$ value for significant relationships. Given the wording in the caption, I was

Printer-friendly version

Discussion paper 
expecting to see information such as $p=0.02, p=0.04, p<0.01$, etc.

References Brevik, E.C., Fenton, T.E., 2004. Effect of changes in bulk density on soil HESSD electrical conductivity as measured with the Geonics EM-38. Soil Survey Horizons 45 (3), 96-102.

Heil, K., Schmidhalter, U., 2012. Characterisation of soil texture variability using the apparent soil electrical conductivity at a highly variable site. Computers \& Geosciences 39, 98-110.

Heilig, J., Kempenich, J., Doolittle, J., Brevik, E.C., Ulmer, M., 2011. Evaluation of electromagnetic induction to characterize and map sodium-affected soils in the northern Great Plains. Soil Survey Horizons 52 (3), 77-88.

Islam, M.M., Meerschman, E., Saey, T., De Smedt, P., Van De Vijver, E., Delefortrie, S., Van Meirvenne, M., 2014. Characterizing compaction variability with an electromagnetic induction sensor in a puddled paddy rice field. Soil Science Society of America Journal 78(2), 579-588.

Lamb, D.W., Mitchell, A., Hyde, G., 2005. Vineyard trellising with steel posts distorts data from EM soil surveys. Australian Journal of Grape and Wine Research 11(1), 24-32.

Interactive comment on Hydrol. Earth Syst. Sci. Discuss., doi:10.5194/hess-2016-93, 2016. 